\title{
BIRD STRIKE VIRTUAL TESTING SIMULATIONS AND RESULTS, FOR PRELIMINARY AIRFRAME DESIGN STRUCTURAL OPTIMIZATION
}

\author{
P.V. PERDIKOULIS ${ }^{1}$, E.E. THEOTOKOGLOU ${ }^{2}$, I.K. GIANNOPOULOS ${ }^{1}$ \\ ${ }^{1}$ Centre of Excellence for Aeronautics, School of Aerospace, Transport and Manufacturing, Cranfield \\ University, Cranfield \\ MK43 0AL, UK \\ Petros.Perdikoulis@cranfield.ac.uk,https:/www.linkedin.com/in/petrosperdikoulis/ \\ i.giannopoulos@cranfield.ac.uk, https://www.cranfield.ac.uk/people/dr-ioannis-giannopoulos-502415 \\ ${ }^{2}$ Department of Mechanics, Laboratory of Testing and Materials, School of Applied Mathematical and \\ Physical Sciences, National Technical University of Athens \\ GR-157 73, Greece \\ stathis@central.ntua.gr, http://www.semfe.ntua.gr/el/faculty-members/theotokoglou
}

Key words: Bird Strike, Fiber Metal Laminate, Aircraft Design, Explicit Finite Element Analysis, Smoothed Particle Hydrodynamics

\begin{abstract}
External airframe structural components facing the aircraft flight direction, are prone to bird collisions. Aircraft manufacturers meet the bird strike airworthiness requirements through physical bird strike testing. Mainly due to the high costs involved in the certification process, recent studies have highlighted the capabilities and benefits of hybrid simulationexperiment techniques that reduce certification costs. The numerical investigation presented herein, studied the bird-strike simulation methodologies implemented to support airframe manufacturers to partially fulfill the current certification airworthiness requirements. The methodology can be also applied during preliminary aircraft parametric design stages. In the current study, the method was applied onto an aircraft wing leading edge preliminary design, which led to design exploration by correlating the leading edge skin materials and thicknesses with the rib pitch positioning. The bird-strike impact model was simulated using the Smoothed Particle Hydrodynamics numerical method using ABAQUS $®$ Explicit finite element package. The materials benchmarked were aluminum alloy 2024-T3, carbon fiber reinforced epoxy IM7/8552 and S2 glass Fiber Metal Laminate GLARE®. The design goal of the case study was to provide with preliminary evidence for impact resistance, quantified as residual permanent structural deformation of the critical structural components for which design charts were drawn and presented herein.
\end{abstract}




\section{INTRODUCTION}

Bird impact accidents have been considered a threat to flight safety since the start of aviation. Since 1912, more than 50 aircraft have been lost, while annual costs for airline operators are estimated to reach over 1 billion dollars [1]. Aviation authorities across the globe have implemented airworthiness requirements which require the aircraft to be certified for safe continue flight and landing, having undergone bird strike events. An example of such certification requirements can be found in Certification Specification 25 for large transport aircraft, issued by the European Aviation Safety Authority (EASA) [2]. Traditionally, Original Equipment Manufacturers (OEMs) conduct certification tests using real birds, typically dead or sedated chickens. These tests are cost-ineffective and they introduce large output data deviations between them, as real birds tend to differ greatly on their physical properties depending on the species. Furthermore, the airworthiness requirements solely define the bird's mass, without specifying restrictions in the bird's morphological properties, resulting in large data scatter between individual tests [3]. Due to the drawbacks related to bird strike testing using real birds, numerical modelling approaches have gained public acceptance defining it a popular research topic.

\section{BIRD STRIKE NUMERICAL MODELLING}

Bird strike events have been heavily researched and many related studies are available in the public domain [3-12]. A vast variety of simulation models, many of which have been correlated
with experimental results, have studied birds impacts on various types of aircraft componerts.
in an effort to generate validated methodologies for birc strike modelling. Based on the aboye
mentioned experimental and numerical research work, the study herdin assumed the SPH
modelling technique for the bird. Initially, a numerical model verification phase was condugted, benchmarking against experimental and other numerical results available in the public domain,

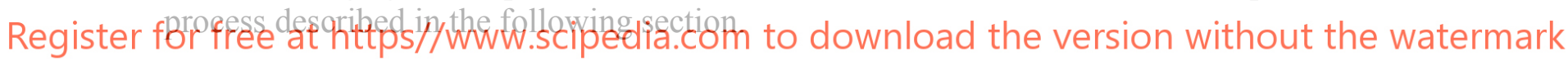

\section{SPH BIRD STRIKE MODELLING VERIFICATION}

Bird strike numerical modelling aims to generate the same impact load on the impacted structural component, in terms of pressure versus time across the impacted area which varies in time as well. Hopkins and Kolsky [13] distinguished between five different impact categories for the behaviour of the impactor named elastic, plastic, hydrodynamic, sonic and explosive. The bird material under similar energy impacts to this study, behaves like a fluid element and for that reason the hydrodynamic category has been found to be the most appropriate description [5]. For deciding the shape of the bird projectile, Hedayati \& Ziaei-Rad [14] presented a comparison study between three available bird modelling methods of Lagrangian, ALE and $\mathrm{SPH}$, which were then further compared against the experimental test data produced by Wilbeck [5]. The bird shape, shown in fig.1, had a hemi-spherical ended cylinder geometry. It was identical for all three methods and for finer mesh discretization, all three approaches predicted results relatively close to the experimental ones. In accordance with current standard practice for bird strike modelling [8], the bird geometry in the current study was designed as a circular cylinder with hemispherical ends, with a cylinder length to diameter ratio equal to two. 


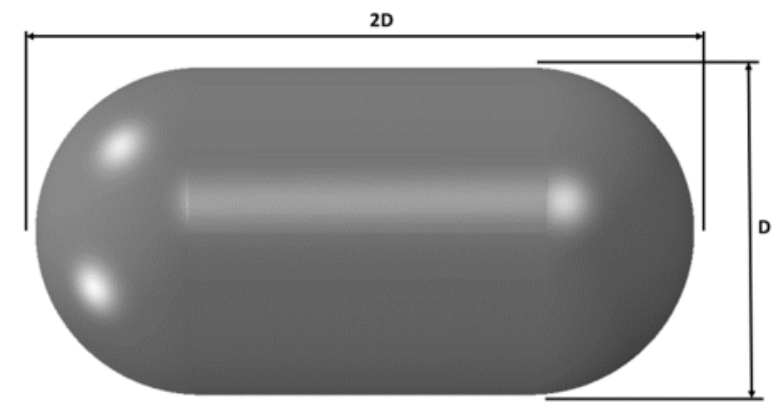

Figure 1: Geometric representation of a bird model

A few key parameters controlling the SPH material properties for bird modelling are needed as input in the ABAQUS software platform. The bird model is assumed to having density of $950 \mathrm{~kg} / \mathrm{m} 3$, due to the assumption of the bird material estimated to be air filled gelatine with $10 \%$ porosity, value measured experimentally by Barber et al [6]. The bird mass was defined by airworthiness certification specification CS 25.631 [2], to be $1.82 \mathrm{~kg}$ (4lb). In order to achieve the required mass, the bird's diameter D, was determined equal to $113 \mathrm{~mm}$, with a similar diameter value also reported in [16].

For the bird numerical modelling validation, simulations were run similar to the analysis of Hedayati \& Ziaei-Rad [14] and compared against the experimental testing from Wilbeck [5], shown in fig. 2 and fig. 3 , where a circular steel plate of $60 \mathrm{~cm}$ in diameter and $6 \mathrm{~mm}$ in thickness was used as target. In the simulation, the plate consisted of 17280 linear hexahedral C3D \& R solid elements having properties of steel. The number of SPH particles resulted from the bird meshing were around, 8,000. The peak pressure on the target plate imposed by the bird was captured as pressure fluctuation on the central plate node. The bird and target plate interdction
was established using a node to surface contact.

The bird model validation was performed by visual comparis on of the SPH particles flow

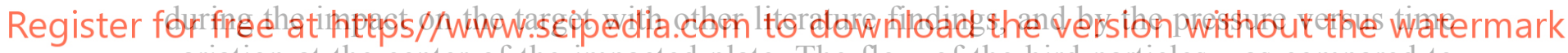
variation at the center of the impacted plate. The flow of the bird particles was compared to [14], with the flow particle showing strong similarities. Additional validation tests with birds having a mass of $0.32 \mathrm{~kg}$ were also conducted, for comparison with a similar study [14]. The bird diameter for the second case was set to $62.2 \mathrm{~mm}$ with the same geometric proportions, and an impact velocity of $116 \mathrm{~m} / \mathrm{s}$. The results obtained were in good agreement with the simulation results of Hedayati \& Ziaei-Rad [14]. 


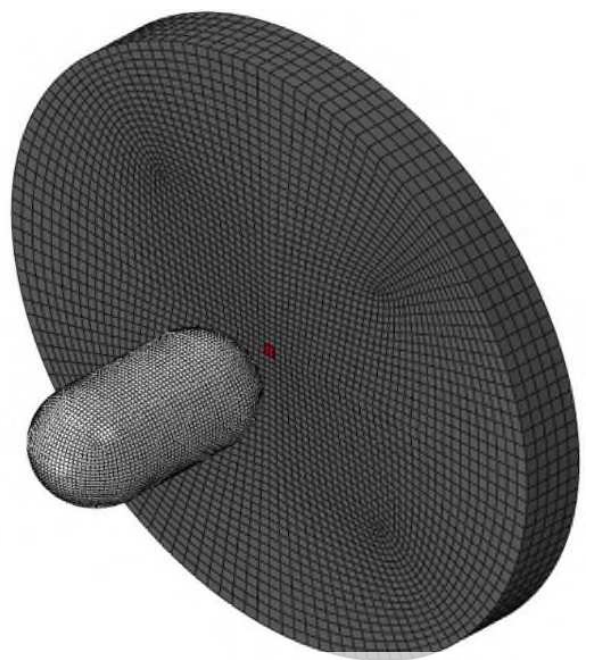

Figure 2: Numerical validation model for the bird SPH modelling parameters
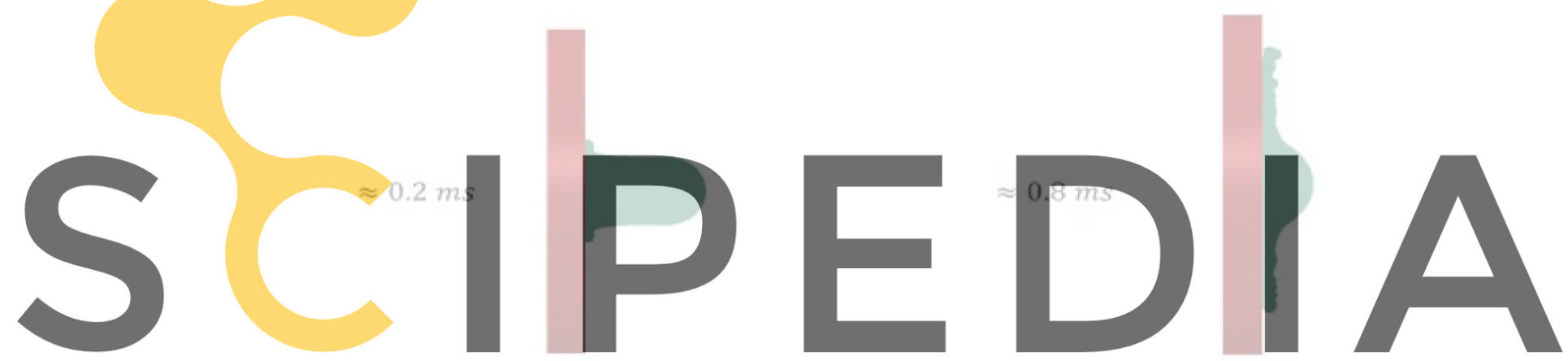

Register for free at https//www.scipedia.com to download the version without the watermark

$\approx 0.5 \mathrm{~ms}$

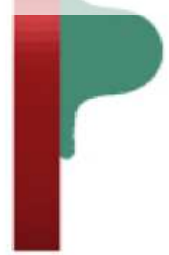

$\approx 1 \mathrm{~ms}$

Figure 3: SPH bird model deformation at different time intervals 
Pressure Data / 1.82 kg Bird Strike

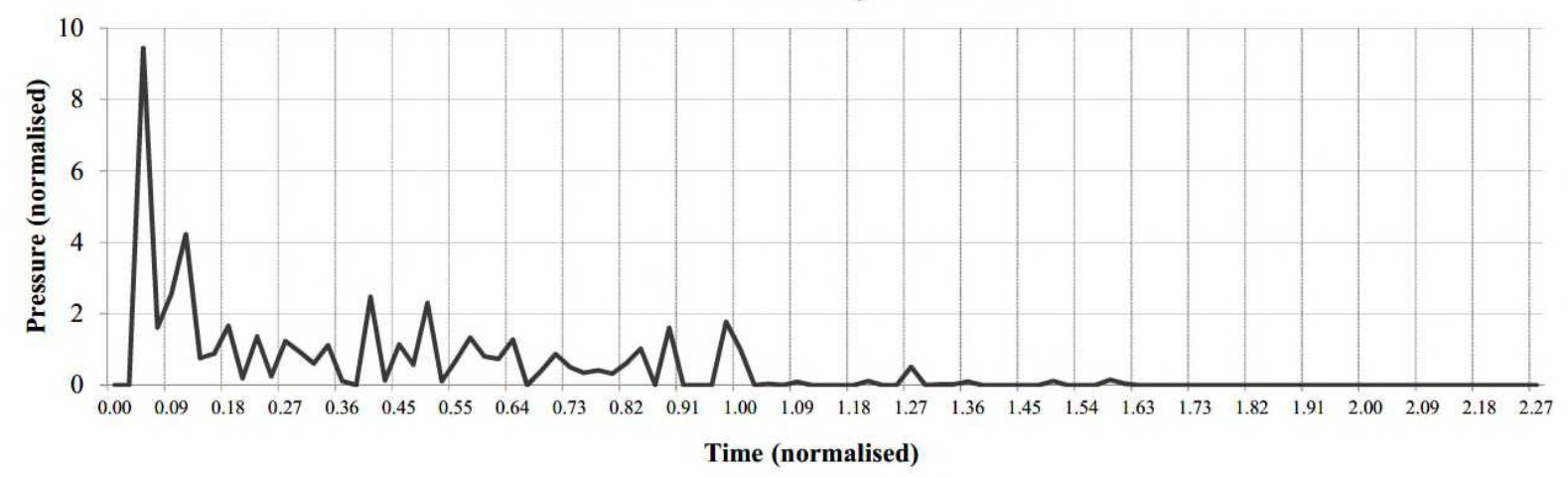

Pressure Data / 0.32 kg bird Strike

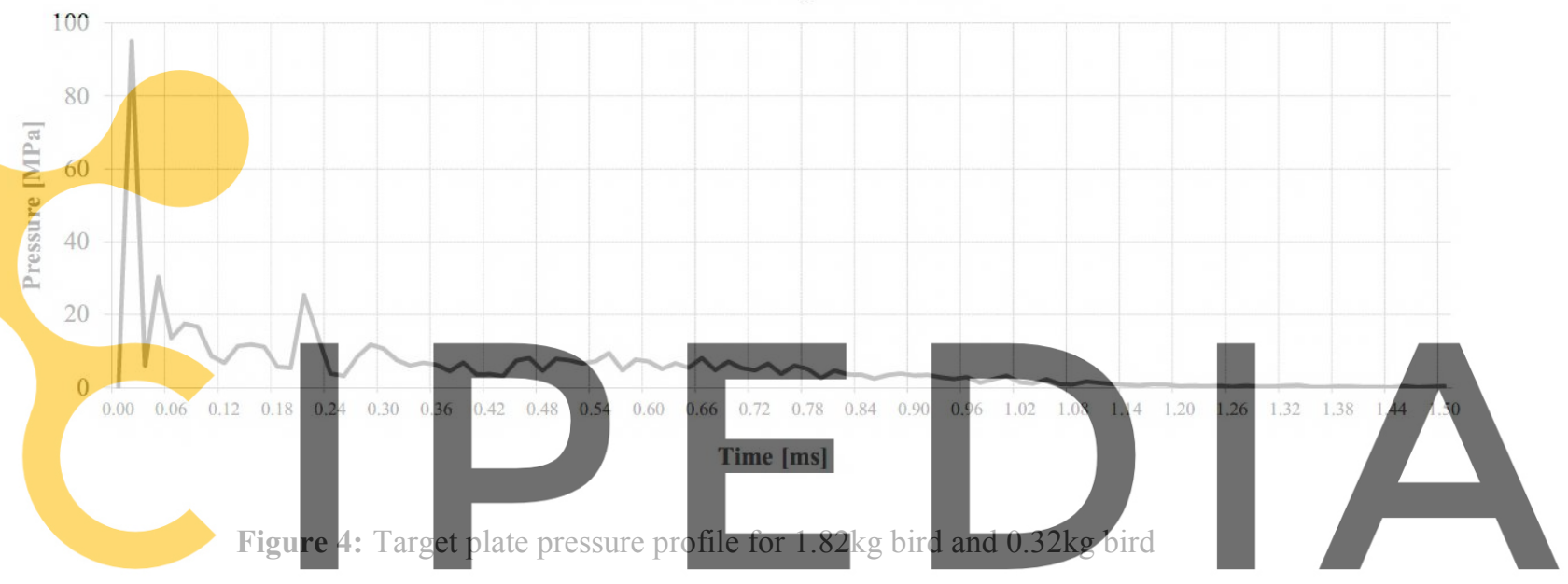

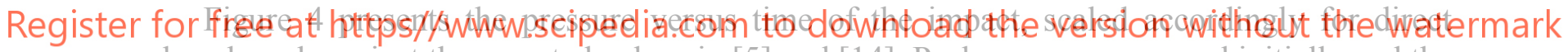
benchmark against the reported values in [5] and [14]. Peak pressure occurred initially and the pressure profile remaining stable with some fluctuations until complete disintegration of the projectile. The peak pressure from the author's simulation was captured at 94.9MPa, while Hedayati \& Ziaei-Rad [14] reported it at 103.9MPa. The simulations conducted for the actual bird size and mass of $1.82 \mathrm{~kg}$ were in good agreement as well. In these, simulations the bird velocity was set to $171 \mathrm{~m} / \mathrm{s}$, so that the same conditions with the literature studies were applied. The number of SPH particles resulted from this bird's mesh was found to be approximately 43,000. In this case, the pressure and time results were normalized, as the literature results were presented in a normalized form. Time was normalized using the expression $t_{N}=\frac{t V_{0}}{2 D}$, with $\mathrm{t}$ the actual time, Vo the bird's initial speed and $\mathrm{D}$ the diameter of the cylinder model, while pressure was normalized using the expression $P_{N}=\frac{P}{\frac{1}{2} \rho_{0} V_{0}{ }^{2}}$, where the normalized pressure is that actual pressure versus a dynamic head comprising of the initial density and speed of the bird. The pressure results for this simulation were compared to Wilbeck's [5] experimental tests, as well as Heimbs FE model [10].

The above benchmarking procedure provided with enough confidence in the SPH modelling 
strategy and parameters adopted for the simulations performed on virtual LE structures.

\section{STRUCTURAL MATERIAL ENERGY ABSORPTION MECHANISMS}

The materials used in the structural modelling were aluminium 2024-T3, GLARE which is a layered material with alternating aluminium and glass fibre reinforce epoxy layers, and IM7/8552 carbon fibre reinforced composite. Apart from the elastic structural deformation for accommodating the energy of the impact, two different material failure energy absorption mechanisms were numerically modelled; a) plasticity modelling for the aluminium skin and the aluminum GLARE layers, and b) damage initiation followed by a linear reduction in the stiffness damage propagation mechanism for the glass and carbon fiber composites [17]. The elastic mechanical properties for the aluminum were obtained from MIL-HDBK 5J [18], while the Johnson-Cook ductile damage plasticity criterion was included in the simulation according to eq.(1).

$$
\bar{\varepsilon}_{0 i}=\left[D_{1}+D_{2} \exp \left(D_{3} \frac{P}{\bar{\sigma}}\right)\right]
$$

The area underneath the stress strain elastoplastic material response assumed by eq.(1), is a measure of the material's capacity to absorb energy, by transforming it into material plasticization.

For both fiber reinfor initiation, shown in propagation law [17].
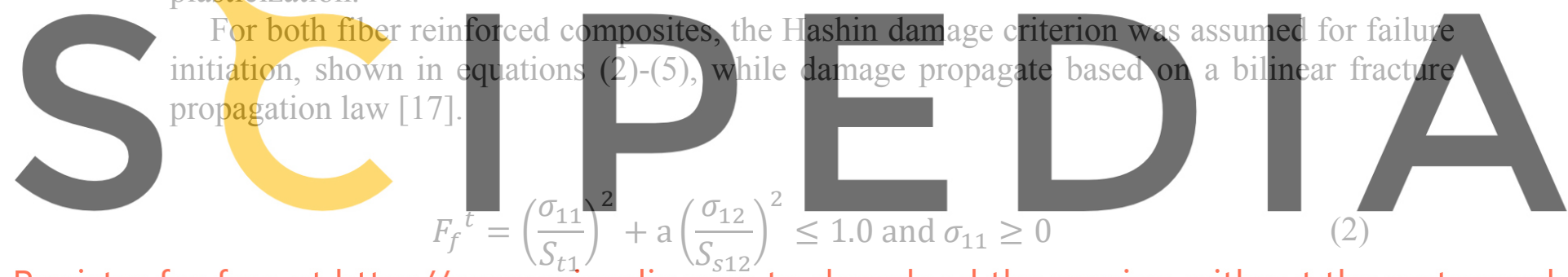

Register for free at https//www.scipedia.çom to download the version without the watermark

$$
\begin{gathered}
F_{f}{ }^{c}=\left(\frac{\sigma_{11}}{S_{c 1}}\right)^{2} \leq 1.0 \text { and } \sigma_{11}<0 \\
F_{m}{ }^{t}=\left(\frac{\sigma_{22}}{S_{t 2}}\right)^{2}+\left(\frac{\sigma_{12}}{S_{s 12}}\right)^{2} \leq 1.0 \text { and } \sigma_{22} \geq 0 \\
F_{m}{ }^{c}=\left(\frac{\sigma_{22}}{2 S_{s 23}}\right)^{2}+\left[\left(\frac{S_{c 2}}{2 S_{s 23}}\right)^{2}-1\right] \frac{\sigma_{22}}{S_{c 2}}+\left(\frac{\sigma_{12}}{S_{s 12}}\right)^{2} \leq 1.0 \text { and } \sigma_{22}<0
\end{gathered}
$$

Equations (2)-(5) represent the points of material failure initiation. By assuming a linear decrease in the material internal resistance to externally applied additional deformation after failure initiation, the measure of energy absorption transforming into the material damage, termed as the material fracture toughness, is then represented by the area sketched underneath the stress deformation bilinear relationship [17]. 


\section{BIRD IMPACT ON CURVED, LEADING EDGE FORM}

The finite element model developed for investigating the relative effects of the skin material, skin thickness and rib positioning to the leading edge structural integrity under bird strike is shown in fig.5. The model is representative of a typical wing LE section and it comprised of an outer skin panel, two ribs and a spar. Fastener attachments were encompassed in the model for a realistic rib attachment to the skin panel, using a built-in function within the software. The airfoil shape was according to NACA0003. The skin panel span was set to $1000 \mathrm{~mm}$ with a finite element mesh consisting of 7200 S4R linear quadrilateral elements. The spar and ribs material was selected to be aluminum alloy 2024-T3, irrespective of the choice of the skin material. The spar web and flange thicknesses were both set at $2.5 \mathrm{~mm}$. Constant thicknesses throughout the simulations were assigned to the rib web and flange, $1.75 \mathrm{~mm}$ and $1 \mathrm{~mm}$ respectively, so that the results would be solely dependent on the LE skin material and thickness. The bird's impact velocity was set to $180 \mathrm{~m} / \mathrm{s}$ and the total simulation time was set at $0.004 \mathrm{sec}$, to allow enough time for the impact to be fully absorbed by the structure, as shown in fig. 6.
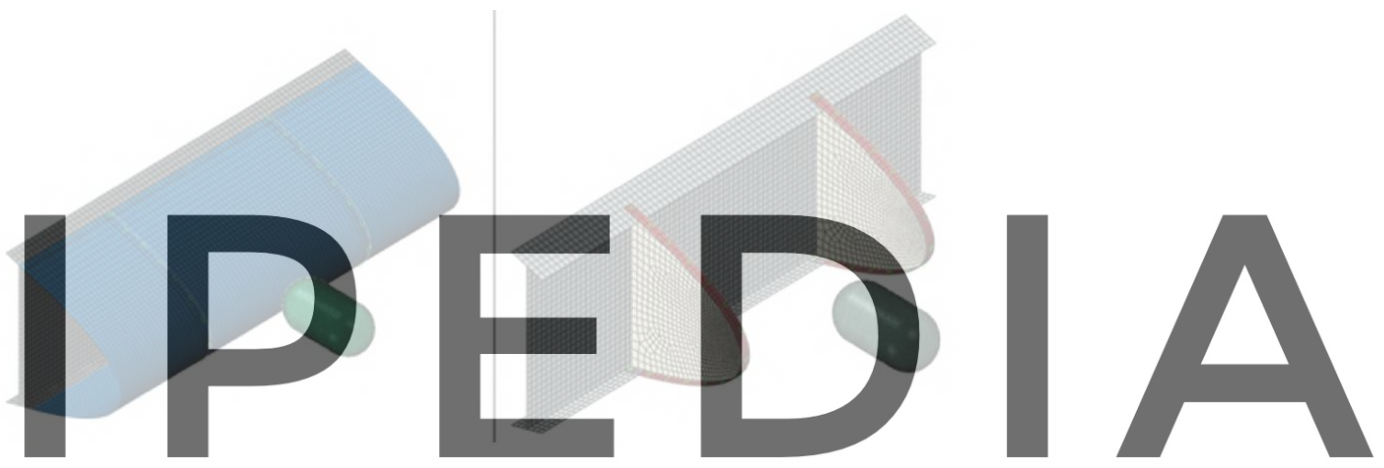

Figure 5: Representative wing LE structure modelled in ABAQUS Register for free at https//www.scipedia.com to download the version without the watermark
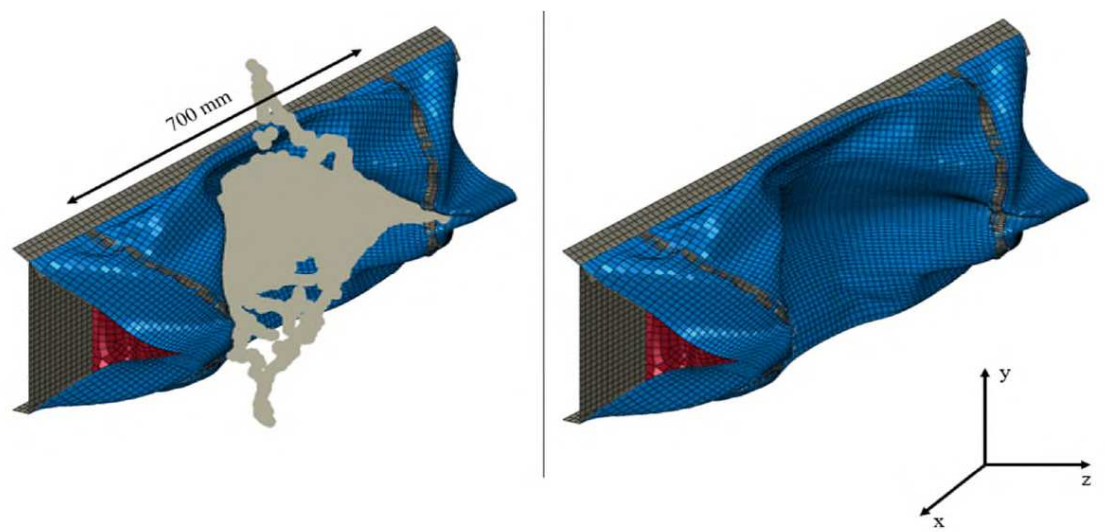

Figure 6: Representative LE total deformation following the bird strike event 
Simulations were run and results were obtained in terms of three rib positions, namely at $300 \mathrm{~mm}, 500 \mathrm{~mm}$ and $700 \mathrm{~mm}$ spacing and for the three different skin materials, aluminum alloy 2024-T3, GLARE and IM7/8552. The FML laminate is produced in pre-specified layups, five of which were chosen for analysis. The other two skin materials thicknesses for the LE, the skin made of aluminum and of IM7/8552 were chosen in thickness to match the GLARE skin predefined weight.

The numerical simulations results are depicted in figure 7, were the spar permanent residual deformation is plotted against the LE skin thickness, for the three materials used. It has to be stretched that the results are governed by the numerical implementation of the material damage modeling for the aluminum and composite materials. Hence, based on the numerical modelling strategy followed, it was found that the aluminum alloy and GLARE panels behaved in a similar manner, having higher impact energy absorption capacity, with the aluminum being slightly more effective than GLARE. On the other hand, the aluminum skin panel penetration along the projectile motion was deeper than for the GLARE panels. This impact resistance benefit of GLARE is important from an airworthiness requirement standpoint, taking into account the Acceptable Means of Compliance AMC 25.631 [2], since lower component deformations result in lower chances of internal structure damage due to impact. The IM7/8552 was less successful than the other two materials. The numerically modelled composite skin was unable to resist and absorb the bird's kinetic energy during all cases, resulting at a considerable spar web deformation. It was found that the bird's frontal

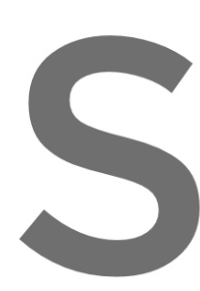
segment was only parti instantly penetrated.
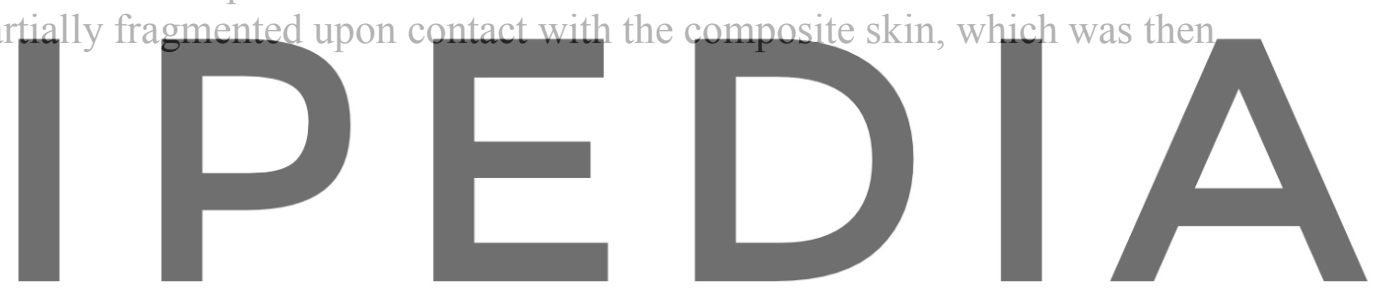

Register for free at https//www.scipedia.com to download the version without the watermark 


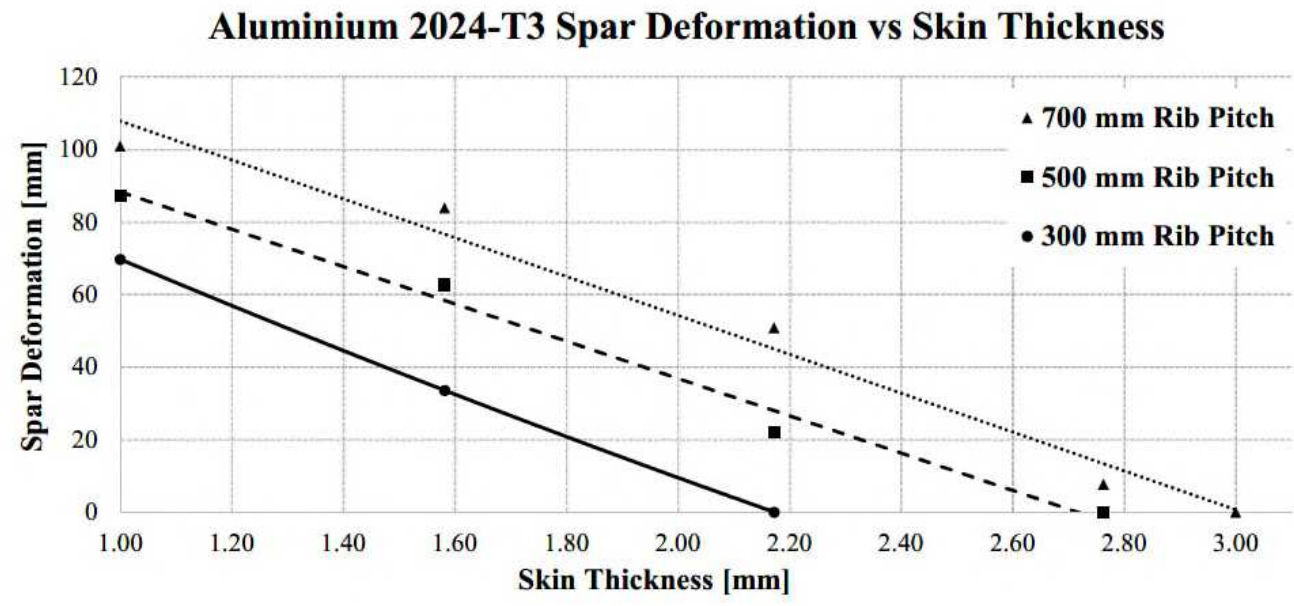

GLARE Spar Deformation vs Skin Thickness
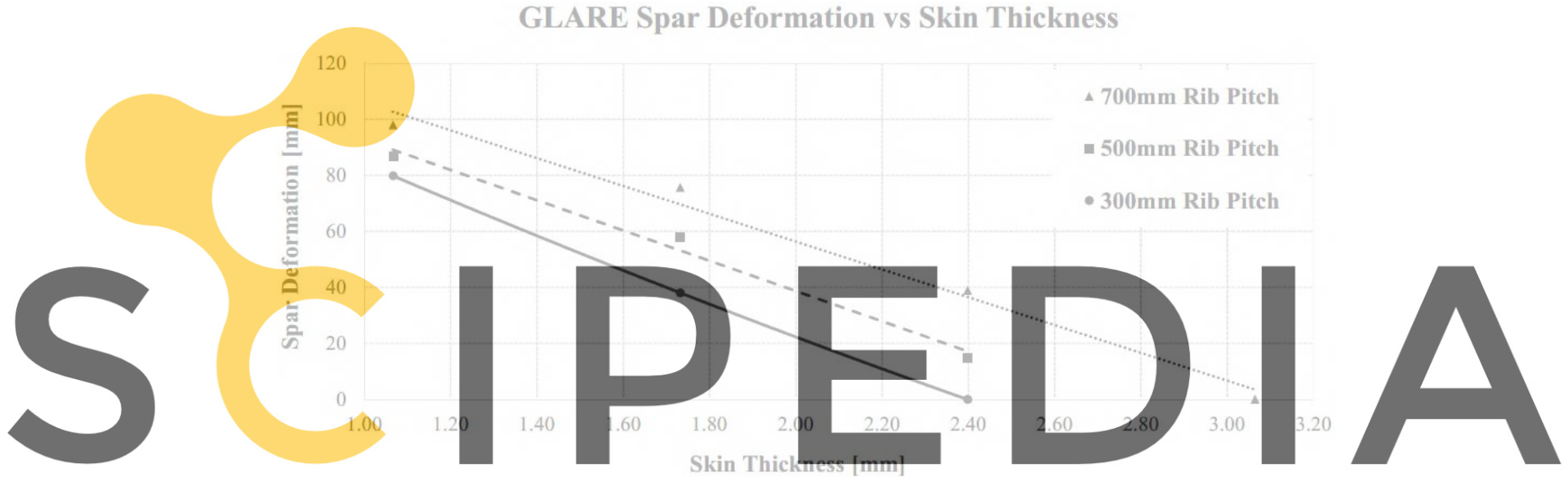

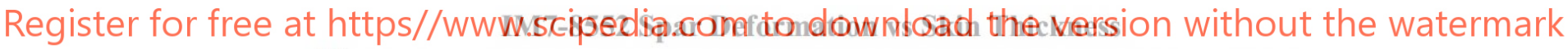

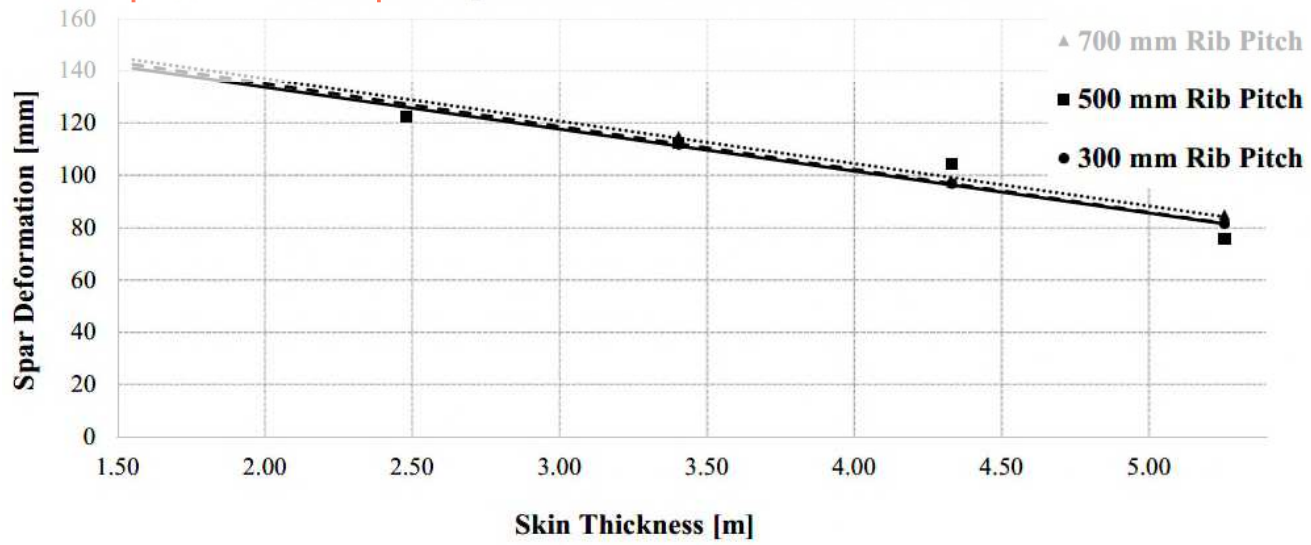

Figure 7: Spar residual deformation versus skin thickness for the various materials numerically investigated 


\section{CONCLUSIONS}

- $\quad$ The study herein, presented the SPH numerical modelling parameters and the path to verification of a numerical model for bird strike events simulations. Numerical results were benchmarked against experimental ones as well as correlated with similar studies, available in the public domain.

- Following the bird model verification, a number of simulations upon a representative leading edge structure were performed and design charts were drawn correlating the skin leading edge material and thickness with the rib positioning.

- Simulations based on the applicable metal plasticity and progressive damage modelling for the composites, showed that the aluminum structure had a better capability of impact energy absorption, while GLARE was able to provide with smaller overall penetration. The carbon fiber leading edge skin did not perform that well.

\section{REFERENCES}

Zienkiewicz, O.C. and Taylor, R.L. The finite element method. McGraw Hill, Vol. I., (1989), Vol. II, (1991).

[2] MacKinnon, B. (2004) Sharing the Skies. An Aviation Industry Guide to the Management of Wildlife Hazards, Sharing the Skies. An Aviation Industry Guide to the Management of Wildlife Hazards. Transport Canada.
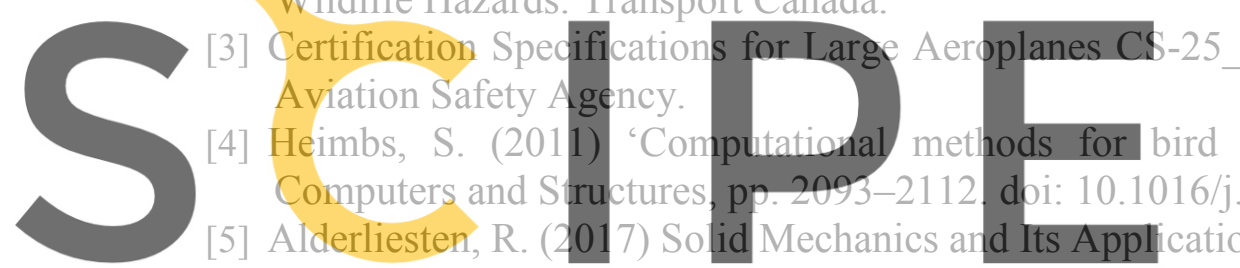
Alderliesten, R. (2017) Solie Mechanics and lis App

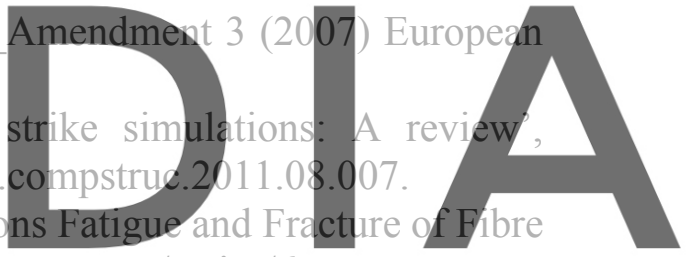
Metal Laminates. Springer. Available at: http://www.springer.com/series/6557.

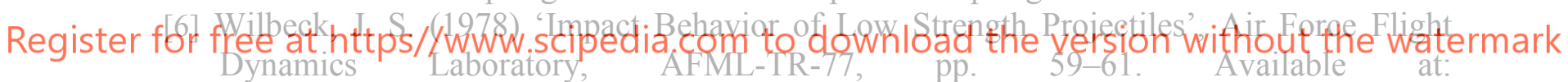
https://apps.dtic.mil/dtic/tr/fulltext/u2/a060423.pdf.

[7] Barber, J., Taylor, H. R. and Wilbeck, J. S. (1978) Bird Impact Forces and Pressures on Rigid and Compliant Targets.

[8] Georgiadis, S., Gunnion, A. J., Thomson, R. S. and Cartwright, B. K. (2008) 'Bird-strike simulation for certification of the Boeing 787 composite moveable trailing edge', Composite Structures, 86(1-3), pp. 258-268. doi: 10.1016/j.compstruct.2008.03.025.

[9] Mccarthy, M. A., Xiao, J. R., Mccarthy, C. T., Kamoulakos, A., Ramos, J., Gallard, J. P. and Melito, V. (2004) Modelling of Bird Strike on an Aircraft Wing Leading Edge Made from Fibre Metal Laminates-Part 2: Modelling of Impact with SPH Bird Model, Applied Composite Materials.

[10]Tho, C.-H. and Smith, M. R. (2008) ACCURATE BIRD STRIKE SIMULATION METHODOLOGY FOR BA609 TILTROTOR. Texas.

[11]Heimbs, S. (2011) 'Bird Strike Simulations on Composite Aircraft Structures', in SIMULIA Customer Conference. Munich, Germany: EADS, Innovation Works.

[12]Kermanidis, T., Labeas, G., Sunaric, M. and Ubels, L. (2005) 'Development and validation of a novel bird strike resistant composite leading edge structure', Applied Composite 
Materials, 12(6), pp. 327-353. doi: 10.1007/s10443-005-3441-z.

[13]Johnson, A. F. and Holzapfel, M. (2003) 'Modelling soft body impact on composite structures', Composite Structures. Elsevier BV, 61(1-2), pp. 103-113. doi: 10.1016/S02638223(03)00033-3.

[14]H. G. Hopkins, and H. Kolsky, 'Mechanics of Hypervelocity Impact of Solids', Proceedings of the Fourth Symposium on Hypervelocity Impact, Air Proving Ground Center, Eglin Air Force Base, Florida, 1960, paper no 12.

[15]Hedayati, R. and Ziaei-Rad, S. (2011) 'A new bird model and the effect of bird geometry in impacts from various orientations', International Journal of Vehicle Structures and Systems, 3(3), pp. 184-191. doi: 10.1016/j.ast.2012.09.002.

[16] Hedayati, R. and Sadighi, M. (2016) Bird strike : an experimental, theoretical and numerical investigation. Cambridge: Woodhead Publishing in Mechanical Engineering, pp. 139.

[17]Langrand, B., Bayart, A. S., Chauveau, Y. and Deletombe, E. (2002) 'Assessment of multiphysics FE methods for bird strike modelling-Application to a metallic riveted airframe', International Journal of Crashworthiness 7(4), pp. 415-428.

[18] Abaqus Analysis User's Guide, 6.14 (2014).

[19] MIL-HDBK-5J, Department of Defense Handbook: Metallic Materials and Elements for Aerospace Vehicle Structures (31 January 2003) [S/S by MMPDS-01]

[20] Wierzbicki, T., Bao, Y., Lee, Y. W. and Bai, Y. (2005) 'Calibration and evaluation of seven fracture models', International Journal of Mechanical Sciences, 47(4-5 SPEC. ISS.), pp. 719-743. doi: 10.1016/j.ijmecsci.2005.03.003.

[21]High Strength Glass Fibers (2006). Available at: https://www.agy.com/wpcontent/uploads/2014/03/High_Strength_Glass_Fibers-Technical.pdf.

[22] Ghafarizadeh, S., Chatelain, J. F. and Lebrun, G. (2016) 'Finite element analysis of surface milling of carbon fiber-reinforced composites', International Journal of Advanced Manufacturing Technology. Springer London, 87(1-4), pp. 399-409. doi: 10.1007/s00170016-8482-y.

[23]Ng, Y., Tomblin, J. and Hooper, E. (2011) Hexcel 8552 IM7 Unidirectional Prepreg 190 gsm \&amp; 35\%RC Qualification Material Property Data Report FAA Special Project Number SP4614WI-Q Revision A. NATIONAL INSTITUTE FOR AVIATION RESEARCH. 